\title{
Shear bond strength between autopolymerizing acrylic resin and Co-Cr alloy using different primers
}

\author{
Sasiwimol SANOHKAN 1 , Somchai URAPEPON ${ }^{2}$, Choltacha HARNIRATTISAI ${ }^{3}$, Chakrit SIRISINHA ${ }^{4}$ \\ and Panya SUNINTABOON ${ }^{4}$ \\ ${ }^{1}$ Dental Biomaterials Program, Faculty of Dentistry, Mahidol University, Yothi Rajthevee Rd., Bangkok, Thailand 10400 \\ ${ }^{2}$ Department of Prosthodontics, Faculty of Dentistry, Mahidol University, Yothi Rajthevee Rd., Bangkok, Thailand 10400 \\ ${ }^{3}$ Department of Operative Dentistry and Endodontics, Faculty of Dentistry, Mahidol University, Yothi Road, Rajthevee, Bangkok, Thailand 10400 \\ ${ }^{4}$ Department of Chemistry, Faculty of Science, Mahidol University, Rama 6 Road, Rajthevee, Bangkok, Thailand 10400 \\ Corresponding author, Somchai URAPEPON; E-mail: dtsor@mahidol.ac.th
}

\begin{abstract}
This study aimed to examine the shear bond strength between cobalt chromium alloy and autopolymerizing acrylic resin using experimental primers containing 5, 10, and $15 \mathrm{wt} \%$ of 4-methacryloxyethyl trimellitic anhydride or 1,2 , and 3 wt $\%$ of 3-methacryloxypropyl-trimethoxysilane comparison to 5 commercial primers (ML primers, Alloy primer, Metal/Zirconia primer, Monobond S, and Monobond plus). Sixty alloy specimens were sandblasted and treated with each primer before bonded with an acrylic resin. The control group was not primed. The shear bond strengths were tested and statistically compared. Specimens treated with commercial primers significantly increased the shear bond strength of acrylic resin to cobalt chromium alloy $(p<0.05)$. The highest shear bond strength was found in the Alloy primer group. Among experimental group, using 10 wt\% of 4-methacryloxyethyl trimellitic anhydride -or $2 \mathrm{wt} \%$ of 3-methacryloxypropyltrimethoxysilane enhanced highest shear bond strength. The experimental and commercial primers in this study all improved bonding of acrylic resin to cobalt chromium alloy.
\end{abstract}

Keywords: Primers, PMMA, Co-Cr alloy, Shear bond strength

\section{INTRODUCTION}

In prosthetic and restorative dentistry, high bond strength between material phases is necessary. The commonly used metal alloys for removable partial dentures (RPD) are cobalt-chromium alloy (Co-Cr alloy). An acrylic denture base is attached to the $\mathrm{Co}-\mathrm{Cr}$ alloy by mechanical interlocking such as retention beads ${ }^{1}$. The absence of chemical bonding between the poly(methyl methacrylate) (PMMA) denture base and the Co-Cr metal framework is a significant clinical problem in removable partial prosthodontics, leading to bond failure and microleakage. So optimizing shear bond strength between acrylic resin and the metal framework is essential for the success of the prosthesis. It was reported that a chemical etching method with Silicoater MD and Kevloc Systems improved retention between PMMA resin and alloys ${ }^{2}$. These systems used to enhance chemical bonding include silanes as a coupling agent on a pyrollytically treated metal surface. However, these techniques are technique sensitive and require special devices. The silane most commonly applied in dental laboratories and chair-side is a monofunctional-3-meth acryloxypropyltrimethoxysilane (3-MPS). The 3-MPS is known to promote the adhesion through chemical and physical coupling between metal-composites, ceramiccomposites, and composites, particularly containing methacrylate groups.

The application of 4-methacryloxyethyl trimellitic

Color figures can be viewed in the online issue, which is available at J-STAGE.

Received Feb 13, 2012: Accepted May 22, 2012

doi:10.4012/dmj.2012-051 JOI JST.JSTAGE/dmj/2012-051 anhydride (4-META) has been promoted as a chemical bonding method for enhancing the bond strength between metal and acrylic resin ${ }^{3)}$. Like carboxylate groups, its acid anhydride moiety should interact with tooth or metal substrates, and its methacrylate moiety can polymerize and copolymerize with monomeric composite resin. The previous studies reported that 4-META adhesive monomer adhered strongly to dental alloy and acrylic resin ${ }^{4-6)}$.

Nowadays, various primers that are developed aim to bond to the metal surface ${ }^{7-10)}$, but there is no report on the comparison of the bond strength among Co-Cr alloy and PMMA using different functional monomers such as 3-MPS, 4-META, MDP, and 6-MHPA. The amount of 4-META and 3-MPS in commercial products in the dental market varied, less than $10 \%$ of 4 -META and $2.5 \%$ of $3-\mathrm{MPS}^{11,12)}$. However, the optimum concentration of 4-META and the 3-MPS in bonding of acrylic resin to $\mathrm{Co}-\mathrm{Cr}$ alloy is unclear.

Regardless of the improvement of bond strength between Co-Cr alloy and PMMA or for the repairing, satisfactory repair must have adequate strength. There are many available primers in dental market but there is no report on the comparison of the bond strength between $\mathrm{Co}-\mathrm{Cr}$ alloy and PMMA using 3-MPS, 4-META, and these commercial primers.

So, the purpose of this study was to determine the shear bond strength of autopolymerized PMMA to Co$\mathrm{Cr}$ alloy when treated with various primers, including experimental primers containing 5, 10, and $15 \mathrm{wt} \%$ of 4-META in acetone, 1, 2, $3 \mathrm{wt} \%$ of 3-MPS in acetone, ML 
primes, Alloy primer, Metal/Zirconia primer, Monobond $\mathrm{S}$, and Monobond plus primer.

\section{MATERIALS AND METHODS}

\section{Primer preparation}

All primers used in this study are shown in Table 1. According to the pilot study, the concentration of $1 \%$, $2 \%$ and $3 \%$ of 3 -MPS and $5 \%, 10 \%$ and $15 \%$ of 4 -META were selected to evaluate in this study. 3-MPS was dissolved in acetone to obtain $1 \%, 2 \%$ and $3 \%$ silane concentration by weight. The $\mathrm{pH}$ was adjusted to 4.5 with $1 \mathrm{M}$ acetic acid. 4-META was prepared in acetone solvent at $5 \%, 10 \%$ and $15 \%$ concentration by weight. All prepared primers were allowed to stabilize for $24 \mathrm{~h}$ at room temperature. The commercial primers that used in this study were ML primer, Alloy primer, Metal/Zirconia primer, Monobond S, and Monobond plus. Non-primed samples served as the control.

\section{Preparation of cast metal discs}

Rectangular wax patterns $(10.0 \times 10.0 \times 2.5 \mathrm{~mm})$ were casted with Cobalt-Chrome PD alloys (BEGO, WilhelmHerbst-Strabe I, Bremen, Germany) according to the manufacturer's instructions. Each casting specimen was then embedded in an autopolymerized acrylic resin block ensuring that one surface of the alloy disc remained uncovered for bonding procedures. The casting surfaces were polished with emery paper No. 240 to 600 under water and sandblasted with $50 \mu \mathrm{m}$ grain-sized aluminum oxide for $10 \mathrm{~s}$, using a grit blaster (Modular Blasting Line, Dentalform, Torino, Italy). The emission pressure was $0.48 \mathrm{MPa}$ with the nozzle positioned approximately $5 \mathrm{~mm}$ from the surface of the metal adherent. The grit-blasted cast disks were washed with steam and then immersed in distilled water for 10 min with an ultrasonic cleanser (Vibraclean 112 model $300, \mathrm{CA}, \mathrm{USA})$. A piece of double-coated tape $(50 \mu \mathrm{m}$ in thickness) with a circular hole of $5 \mathrm{~mm}$ in diameter was placed on the specimen to define the bonding area. The specimens were divided into 12 groups with 5 specimens per group according to the primer used. In the control groups, the sandblasted surfaces were bonded without using any primer. For the experimental groups, each primer was applied directly to the Co-Cr disc alloy with a brush and allowed to react for $30 \mathrm{~min}$.

A silicone mold with a cylindrical hole of $5 \mathrm{~mm}$ in diameter and $5 \mathrm{~mm}$ in height was placed on the metal surface. An autopolymerizing acrylic resin (Ortho-Jet ${ }^{\circledR}$, Lang Dental MFG.Co.,Inc., IL, USA, Lot No. 1380-4006) was mixed according to the manufacturers' instructions, until it reached a dough consistency and packed into the silicone mold. After complete curing, which took $30 \mathrm{~min}$, the specimens were carefully removed from the silicone mold and immersed in water at $37^{\circ} \mathrm{C}$ for $24 \mathrm{~h}$ before shear bond strength testing.

\section{Shear bond strength testing}

The specimens were mounted in a universal testing machine (Instron model 5566, Instron Corporation, Buckinghamshire, UK) and the shear bond strength was evaluated at a crosshead speed of $0.5 \mathrm{~mm} / \mathrm{min}^{13)}$. The apparatus consisted of parallel guides, a tube holder, and a load cell of $1 \mathrm{KN}$. The apparatus ensured that the tube was perpendicular to the sample surface (Fig. 1). The blade started to shear $2 \mathrm{~mm}$ above the metal

Table 1 Materials used for this study

\begin{tabular}{|c|c|c|}
\hline Primers & Functional monomers & Manufacturers \\
\hline $\begin{array}{l}\text { Experimental } \\
3 \text {-MPS }\end{array}$ & $\begin{array}{c}\gamma \text {-methacryloxypropyltrimethoxy silane } \\
(1,2,3 \mathrm{wt} \%) \text { in acetone }\end{array}$ & $\begin{array}{l}\text { Evonik Degussa, Marl, Germany } \\
\text { (Lot No. 2390612802) }\end{array}$ \\
\hline $\begin{array}{l}\text { Experimental } \\
\text { 4-META }\end{array}$ & $\begin{array}{l}\text { 4-methacryloxyethyl trimellitate anhydride } \\
\qquad(5,10,15 \mathrm{wt} \%) \text { in acetone }\end{array}$ & $\begin{array}{l}\text { Sun Medical Co.Ltd., Tokyo, Japan } \\
\text { (Lot No. T1003) }\end{array}$ \\
\hline ML primer & 6-MHPA Phosphonate and thioctic acid in acetone & $\begin{array}{l}\text { Shofu Inc., Kyoto, Japan } \\
\text { (Lot No. 110835) }\end{array}$ \\
\hline Alloy primer & VBATDT and 10-MDP in acetone & $\begin{array}{c}\text { Kuraray Medical Co., Ltd., Osaka, Japan } \\
\text { (Lot No. 00325A) }\end{array}$ \\
\hline $\begin{array}{l}\text { Metal/Zirconia } \\
\text { primer }\end{array}$ & Phosphonic acid acrylate in tert-Butyl alcohol & $\begin{array}{l}\text { Ivoclar Vivaden, Schaan, Liechtenstein } \\
\text { (Lot No. K11988) }\end{array}$ \\
\hline Monobond S & 3-MPS in ethanol & $\begin{array}{l}\text { Ivoclar Vivadent, Schaan, Liechtenstein } \\
\text { (Lot No. K 06475) }\end{array}$ \\
\hline Monobond plus & $\begin{array}{l}\text { Silane methacrylate, phosphoric acid ester, } \\
\text { sulphide methacrylate, ethanol }\end{array}$ & $\begin{array}{c}\text { Ivoclar Vivadent, Schaan, Liechtenstein } \\
\text { (Lot No. M24811) }\end{array}$ \\
\hline
\end{tabular}

10-MDP, 10-metha cryloxydecyldihydrogenphosphate

6-MHPA, 6-methacryloxyhexyl- phosphonoacetate

VBATDT, 6-(4-vinylbenzyl-n-propyl)amine-1,3,5-triazine-2,-4-dithiol 
on the sample. The force at which the bond failed was recorded, and then the bond strength was calculated in Megapascals (MPa).

The site of bond failure and the surface morphology of the debonded specimens were examined with a scanning electron microscope (SEM, Model JSM-5410 LV, JEOL LTD., Tokyo, Japan). Fracture surfaces were examined under optical microscope (Eclipse G400 POL;

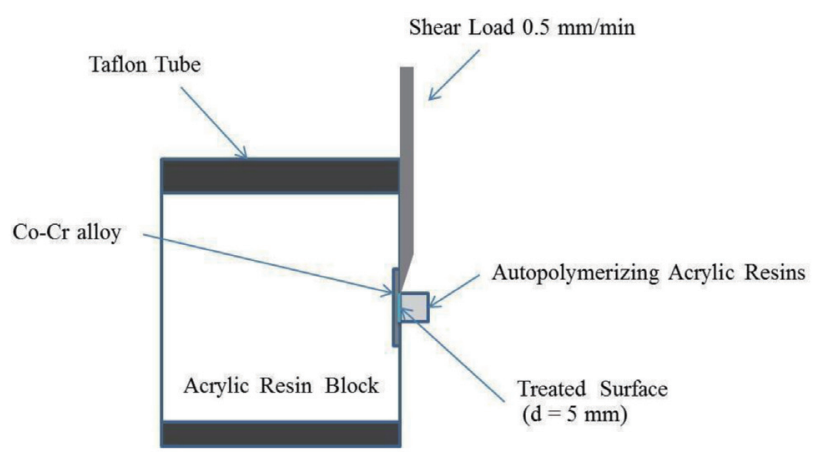

Fig. 1 Shear test apparatus (d=diameter).
Nikon, Tokyo, Japan) at $\times 20$ magnification. The mode of failure was classified as "adhesive" when the remaining material on the alloy surface was less than $25 \%$, "cohesive" when it was more than $75 \%$, and "combination" when it ranged between $25 \%-75 \%{ }^{14)}$.

\section{Statistical analysis}

The recorded shear bond strength values were analyzed. Means and standard deviation were computed and the interaction between primer and substrate were evaluated by one-way ANOVA. When a significant difference was noted, the multiple comparison test using Tukey HSD was used to determine the pair differences. The statistical differences were evaluated at a significance level of 0.05 .

\section{RESULTS}

Table 2 summarizes the means and standard deviations (SD) of the shear bond strength between acrylic resins and $\mathrm{Co}-\mathrm{Cr}$ alloy using 5, 10, $15 \mathrm{wt} \%$ of 4-META, 1, 2, and $3 \mathrm{wt} \%$ of 3-MPS, Alloy primer, ML primer, Metal/ Zirconia primer, Monobond S, and Monobond Plus. The one-way ANOVA results are summarized in Table 3.

Table 2 Mean shear bond strengths (MPa) and standard deviation (SD) of the control and all experimental groups

\begin{tabular}{ccr}
\hline Group & Primer & Shear bond strengths \\
Group 1 & Without primer & $5.05 \pm 0.19^{\mathrm{h}}$ \\
Group 2 & 5 wt\% of 4-META & $10.84 \pm 0.14^{\mathrm{d}}$ \\
Group 3 & 10 wt\% of 4-META & $11.71 \pm 0.18^{\mathrm{c}}$ \\
Group 4 & 15 wt\% of 4-META & $10.64 \pm 0.21^{\mathrm{d}}$ \\
Group 5 & 1 wt\% of 3-MPS & $10.19 \pm 0.24^{\mathrm{e}}$ \\
Group 6 & 2 wt\% of 3-MPS & $9.18^{\mathrm{g}}$ \\
Group 7 & 3 wt\% of 3-MPS & $12.01 \pm 0.20^{\mathrm{f}}$ \\
Group 8 & ML primer & $15.08 \pm 0.14^{\mathrm{c}}$ \\
Group 9 & Alloy primer & $10.04 \pm 0.15^{\mathrm{e}}$ \\
Group 10 & Metal/Zirconia primer & $8.77 \pm 0.17^{\mathrm{g}}$ \\
Group 11 & Monobond S & $13.87 \pm 0.24^{\mathrm{b}}$ \\
\hline
\end{tabular}

Different superscript letters indicate significant difference at $95 \%$ confident.

Table 3 Summary of one-way ANOVA

\begin{tabular}{|c|c|c|c|c|c|}
\hline Source of variation & Degree of freedom & Sum of Squares & Mean Square & $F$-value & $P$-value \\
\hline Between Groups & 11 & 367.32 & 33.39 & 975.80 & 0.00 \\
\hline Within Groups & 48 & 1.64 & 0.03 & & \\
\hline Total & 59 & 368.96 & & & \\
\hline
\end{tabular}




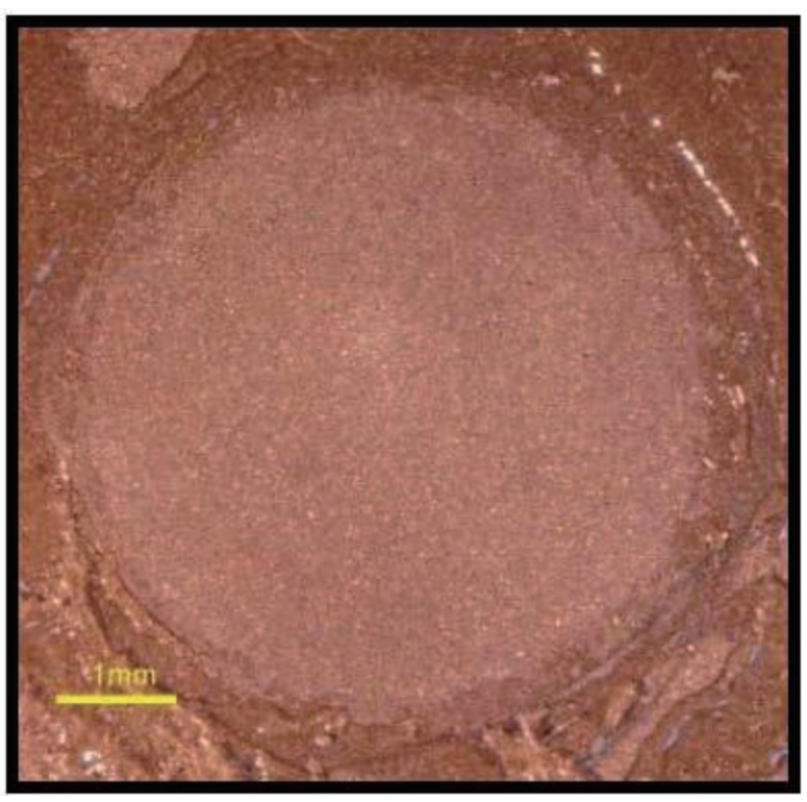

Fig. 2 Optical microscope image illustrating adhesive failure.

The results indicated that using experimental and commercial primers significantly improved the shear bond strengths of acrylic resin to the sandblasted metal surface compared with the control group (non-primed group). No significant differences were detected between $10 \mathrm{wt} \%$ of 4 -META $(11.71 \pm 0.18 \mathrm{MPa})$ and the ML primer group (12.01 $\pm 0.14 \mathrm{MPa})$. Shear bond strength values for alloys treated with $2 \mathrm{wt} \%$ of the 3 -MPS group (10.19 $\pm 0.24 \mathrm{MPa})$ did not differ significantly from the Metal/Zirconia group $(10.04 \pm 0.15 \mathrm{MPa})$. With 1 wt\% of 3-MPS the shear bond strength results did not differ statistically from the Monobond $\mathrm{S}$ group $(p>0.05)$. Figure 2 show representative optical microscope with $\times 20$ magnification images of the fracture surface. All specimens tested in this study showed adhesive failure. No cohesive failure within PMMA was found in this study.

\section{DISCUSSION}

This study attempts to compare the effect of various primers on the shear bond strength between $\mathrm{Co}-\mathrm{Cr}$ alloy and autopolymerizing acrylic resin. It is known that the bonding mechanism between acrylic resin and metal alloy substrate is a combination of chemical and micromechanical bonding or either methods. In this study, all $\mathrm{Co}-\mathrm{Cr}$ alloys were sandblasted with $50 \mu \mathrm{m} \mathrm{Al}_{2} \mathrm{O}_{3}$ particles to create surface roughness. Sandblasting with $\mathrm{Al}_{2} \mathrm{O}_{3}$ particles removes contaminated layers and creates a roughened surface which provides mechanical interlocking for the acrylic resin as well as providing a great surface area for the bond. It has been reported that the sandblasting process makes the-alloy-water contact angle smaller and wettability greater ${ }^{15)}$. According to Yoshida et al. ${ }^{16)}$, metal sandblasting with $\mathrm{Al}_{2} \mathrm{O}_{3}$ particles could form a passive film made of $\mathrm{Ni}, \mathrm{Cr}$, and Co oxides. Ohno et al. ${ }^{17)}$ defined the passive film of hydrated chromium oxyhydroxide and generalized this film by the formula: $\mathrm{Cr}_{\mathrm{x}}(\mathrm{OH})_{3.2} \mathrm{nH}_{2} \mathrm{O}$, which is capable of forming on stainless steel and alloys containing $\mathrm{Ni}$, Co, and $\mathrm{Cr}$. Several chemical methods capable of enhancing the bonding of veneer resin to cast alloys have been reported including an adhesive heat-cured opaque resin, a Silicoater system, a silane coupling agent and adhesive metal primer, a self-curing 4-META/MMA-TBB opaque resin, a light-cured 4-MET opaque resin, and other commercial adhesive bonding promoters. The functional monomers residing in each primer have an affinity with the layer of chromium oxide surfaces. Therefore, the mechanical and chemical factors for bonding are indispensable in creating a stable bond between the acrylic resin and the surface of metal alloy. In this study, the alloy specimens in the control group were blasted without priming and the results showed lower shear bond strength than those of primed groups. The non-primed specimens yielded $5.05 \pm 0.19 \mathrm{MPa}$ which is comparable to the relatively limiting low bond value of 5 MPa specified in ISO 10477 ${ }^{13)}$. This bond strength value, however, is lower than the resin-metal bond strength of $10 \mathrm{MPa}$ suggested by Matsumura et al., as a minimum clinically relevant value ${ }^{18)}$.

The result of our study also suggested that the experimental primers, both 4-META and 3-MPS, increase the bond of acrylic resin to the Co-Cr alloy surface. The bond strength of these primer are equivalent to some commercial primers (Table 2), although the strength was not the highest compared to all commercial primers in this study. Previous studies reported the successful adhesion of denture base resin to cast metal alloys by using 4-META ${ }^{19,20)}$. The chromium content in the Co-Cr alloy produces an oxide layer at room temperature which can enhance chemical bonding with 4-META ${ }^{21)}$. According to Urapepon et al. ${ }^{22)}$, they reported that 4-META has an ability to bond metal oxide on Ag-Sn filler particle to polymeric matrix in a metal-resin composite. Moreover, this study also reported in depth that different oxide form $\left(\mathrm{SnO}\right.$ and $\mathrm{SnO}_{2}$ ) produced different adhesion ability of 4-META. The SnO oxide form exhibited better adhesion to 4-META and Ag-Sn particle than $\mathrm{SnO}_{2}$. Similarly, the present study illustrates the improvement in shear bond strengths between a Co-Cr alloy and auto-polymerizing acrylic resin when using a 5, 10, and $15 \mathrm{wt} \%$ 4-META primer. However, the use of $10 \mathrm{wt} \%$ 4-META offers the highest shear bond strength. It is possible that at 10 wt\% of 4-META, optimal amount of carboxylic group to react with $\mathrm{Co}-\mathrm{Cr}$ oxide layer are obtained. This may suggest that $10 \mathrm{wt} \%$ of 4 -META in acetone is the optimum content for bonding resin to $\mathrm{Co}-\mathrm{Cr}$ alloy.

In practice, 3-MPS is the most routinely used in the clinic $^{12)}$. The rationale for this study was that the selected 3-MPS coupling agent was thought to react with the hydroxyl groups on the $\mathrm{Co}-\mathrm{Cr}$ alloy surface. Therefore, it becomes a crosslinking structure composed 
by intermolecular bonding of the methoxy group with autopolymerizing acrylic resin. The commercial silane primer, 3-MPS, is diluted in a binary solvent, i.e., a water/ethanol or water/methanol solution ${ }^{23}$. The study of a 3-MPS primer in hexane was also reported by Kurata and Yamazaki ${ }^{24)}$. Matinlinna et al. ${ }^{25)}$, studied the effect of 2-propanol solvent and acetone-water to 3-MPS and vinylsilane for bonding of composite resin to titanium metal. In their study, 3-MPS and vinylsilane in acetonewater appeared as a slightly milky solution. However, in our study, the 3-MPS was prepared in acetone and the solution was clear.

There are 2 available forms of silane coupling agents on the market, one bottle in a pre-hydrolyzed form or in a form where hydrolysis occurs by mixing silane and acid (thus, two bottles) ${ }^{26,27}$. The function of acid is to hydrolyze the silane ester group (-Si-O-CH 3 ) to silanol (-Si-OH). The optimum time for adsorption from a silane solution is after hydrolysis and before oligomerization, since the silane coupling agents are most effective when adsorbed as monomers. At $\mathrm{pH} 4-5$, the rate of condensation between silanol groups of monomeric silane molecules to larger oligomers is minimal, and the stability of silane solutions is highest at a pH of about $4^{28)}$. In this study, the acetic acid is used for the $\mathrm{pH}$ adjustment to 4.5 according to previous study ${ }^{28}$. The result showed that priming sandblasted $\mathrm{Co}-\mathrm{Cr}$ alloy with 1, 2, $3 \mathrm{wt} \%$ of 3-MPS could increase the shear bond strength and at $2 \mathrm{wt} \%$ of 3-MPS showed the highest shear bond strength. When the results of the group using $2 \mathrm{wt} \%$ of 3 -MPS were compared to that of Monobond S, which also used 3-MPS as an active agent, the use of $2 \mathrm{wt} \%$ of 3 -MPS provided higher bond strength. However, there was no statistical significant difference in $1 \mathrm{wt} \%$ of 3-MPS and Monobond S. While the concentration of 3-MPS in Monobond S is unknown, this may imply that the concentration of 3-MPS in Monobond S might be less than $2 \%$.

In this study, compared with commercial primers, the Alloy primer revealed the highest shear bond strengths $(15.08 \pm 0.13 \mathrm{MPa})$, followed by the Monobond plus group $(13.87 \pm 0.24 \mathrm{MPa})$. There is no statistical significant difference in $10 \mathrm{wt} \%$ of 4-META $(11.71 \pm 0.18$ $\mathrm{MPa})$ and the ML primer group $(12.01 \pm 0.14 \mathrm{MPa})$. Alloy primer comprises VBATDT (6-(4-vinylbenzyl-npropyl) amino-1,3,5-triazine-2,4-dithione) and 10-MDP (10-methacryloxydecyl dihydrogen phosphate) in acetone solvent. VBATDT reacts with noble metal alloys. The MDP monomer consists of 3 different functioning components; methacryloyl, decyl and dihydrogen phosphate groups. The dihydrogen phosphate group in MDP presents great chemical bonding to metal oxides of chrome formed in the surface of the $\mathrm{Co}-\mathrm{Cr}$ alloy ${ }^{29}$. There are published works reporting the superior effectiveness of MDP to 4-META ${ }^{7,29)}$. The result in this study was similar to the previous studies, indicating the superior effectiveness of the MDP monomer over the carboxylic 4-META monomer. This is probably because of the interaction between the di-hydrogen phosphoric group in MDP and the passive oxide layers formed on the alloy surface. It has been reported that the MDP exceeded the 4-META monomer in bonding ability to the base metal alloy ${ }^{30}$.

For the ML primer, it consists of 10-methacryloyloxydecryl-6,6-dithiooctanoate (MDDT) and an ester phosphate group of 6-methacryloxyhexylph osphonoacetate (6-MHPA) in an acetone solvent. The ML primer is effective for bonding to noble metal and base metal alloy. It showed ability to enhance shear bond strength between $\mathrm{Co}-\mathrm{Cr}$ alloy and auto-polymerizing acrylic resin. In this study, the initial shear bond strength $(24 \mathrm{~h})$ between $\mathrm{Co}-\mathrm{Cr}$ alloy and auto-polymerizing acrylic resin in the ML primer group was lower than the Alloy primer group. This might be due to the fact that the longer hydrocarbon connecting segment in the MDP yields more hydrophobicity and flexibility than the 6-MHPA. However, there is no report the difference in bonding characteristics between a phosphate monomer (MDP) and phosphonate monomer (6-MHPA) when used to bond $\mathrm{Co}-\mathrm{Cr}$ alloy and auto-polymerizing acrylic resin. Koizumi et al. ${ }^{31)}$, reported that there is no difference between MDP and 6-MHPA primer on the shear bond strength of titanium alloy to Super-Bond C\&B resin.

Metal/Zirconia primer consists of phosphonic acid acrylate. The manufacturer claimed that it is suitable for oxide ceramic and all type of metal alloy. In this study, the result showed that the efficiency of Metal/ Zirconia primer in enhancing shear bond strength $(24 \mathrm{~h})$ between $\mathrm{Co}-\mathrm{Cr}$ alloy and auto-polymerizing acrylic resin was inferior to Alloy primer, Monobond Plus, ML primer, and $10 \mathrm{wt} \%$ of 4-META. Alloy primer and Monobond Plus contain methacrylic phosphoric acid monomer, ML primer contains methacrylic phosphonic acid monomer, and Metal/Zirconia primer contains acrylic phosphonic acid monomer. For 4-META, it is comprised of carboxylic acid group. The different structure of adhesion monomers could have different effect on the bond strength.

Recently, Monobond Plus has been introduced to the dental market. The manufacturer claimed that it is a universal primer for all types of restorative materials. Monobond Plus contains 3-MPS, phosphoric acid methacrylate and sulphide methacrylate in an alcohol solution but the chemical structure of functional monomers were not reported. Attia et al. ${ }^{32)}$ reported that the Monobond plus was very efficient for bonding resin to zirconia. However, there are no earlier reports regarding the use of Monobond Plus for bonding $\mathrm{Co}-\mathrm{Cr}$ alloy to acrylic resin.

Alloy primer, ML primer, and Monobond Plus contain a phosphoric acid derivative which can react with metal oxides and create the bonding. This might a possible explanation for their high bond strength.

Monobond-S, which was used in the present study, is a single-component silanizing agent designed to promote the adhesion of ceramic materials to luting composites. Its component is the mixture of ethanol, water, and 3-MPS. The results showed that the shear bond strength in the Monobond S (8.77 $\pm 0.17 \mathrm{MPa})$ group was lower than the $2 \mathrm{wt} \%$ of 3 -MPS primer $(10.19 \pm 0.24$ $\mathrm{MPa}$ ). Nevertheless, it must be kept in mind that 3-MPS silane is not intended in general as a metal conditioner 
but it can enhance the shear bond strength between composite resin and porcelain $^{33)}$. All specimens showed adhesive failure in the metal-resin interface because of the bonding between primer and metal did not overcome the cohesive resistance of PMMA resin.

Finally, the long-term minimum bonding force value that the resin-metal interface has to withstand in order to have a good clinical performance is still unknown. According to the requirements of ISO 10477, the minimum acceptable bond strength value is $5 \mathrm{MPa}^{13)}$. In this study, the results observed in $10 \mathrm{wt} \%$ of 4 -META, $2 \mathrm{wt} \%$ of 3 -MPS, the ML primer, the Alloy primer, the Monobond plus, and the Metal/Zerconia primer improved the initial shear bond strength $(24 \mathrm{~h})$ between $\mathrm{Co}-\mathrm{Cr}$ alloy and auto-polymerizing acrylic resin.

\section{CONCLUSION}

Within the limitations of this study, the following conclusions were drawn:

1. $\gamma$-methacryloxypropyltrimethoxysilane (3-MPS) in acetone and 4-methacryloxyethyl trimellitate anhydride (4-META) were effective to bond autopolymerizing acrylic resin to $\mathrm{Co}-\mathrm{Cr}$ alloy, and $2 \mathrm{wt} \%$ of 3 -MPS and $10 \mathrm{wt} \%$ of 4 -META were the most effective concentrations for bonding.

2. Commercial primers such as ML primer, Alloy primer, Monobond Plus, and Metal/Zerconia primer would probably be clinically acceptable for the improvement in shear bond strength between Co-Cr alloy and auto-polymerizing acrylic resin.

\section{ACKNOWLEDGMENTS}

The authors would like to thank the Research Unit at the Faculty of Dentistry, Mahidol University for their supporting throughout the project. Special thanks to Evonik Degussa (SEA) Pte. Ltd. Singapore (Mr John Ng), Sun Medical Co.,Ltd., Japan and Unity Thailand for donating materials to our study.

\section{REFERENCES}

1) Shue SL, Nicholls JI, Townsend JD. The effect of metal retentive designs on resin veneer retention. J Prosthet Dent 1987; 58: 297-305

2) Pesun S, Mazurat RD. Bond strength of acrylic resin to Cobalt-Chromium alloy treated with the Silicoater MD and Kevloc Systems. J Can Dent Assoc 1998; 64: 798-802.

3) Tulunoglu IF, Oktemer M. Tensile strength and microleakage of the bond between a nickel-chromium alloy and a visible light cured resin composite: effect of 4-META, silicoating, and bead retention. Quintessence Int 1997; 28: 447-451.

4) Matsumura H, Tanaka T, Atsuta M. Effect of acidic primers on bonding between stainless steel and auto-polymerizing methacrylic resins. J Dent 1997; 25: 285-290.

5) Tanaka T, Fujiyama E, Shimuzu H, Takaki A, Atsuta M. Surface treatment of nonprecious alloys for adhesion-fixed partial dentures. J Prosthet Dent 1986; 55: 456-462.

6) Jacobson TE, Chang JC, Keri PP, Watanabe LG. Bond strength of 4-META acrylic resin denture base to cobalt chromium alloy. J Prosthet Dent 1988; 60: 570-576.

7) Ohkubo C, Watanabe I, Hosoi T, Okabe T. Shear bond strengths of poly(methyl methacrylate) to cast titanium and cobalt chromium frameworks using five primers. J Prosthet Dent 2000; 83: 50-57.

8) Freitas AP, Francisconi PAS. Effect of a metal primer on the bond strength of the resin-metal interface. J Appl Oral Sci 2004; 12: 113-116.

9) Shimizu H, Kurtz KS, Tachii Y, Takahashi Y. Use of metal conditioners to improve bond strengths of autopolymerizing denture base resin to cast Ti-6Al-7Nb and Co-Cr. J Dent 2006; 34: 117-122.

10) Bulbul M, Kesim B. The effect of primers on shear bond strength of acrylic resins to different types of metals. J Prosthet Dent 2010; 103: 303-308.

11) Chang JC, Hurst TL, Hart DA, Estey AW. 4-META use in dentistry: A literature review. J Prosthet Dent 2002; 87: 216 224.

12) Matinlinna JP, Lassila LV, Özcan M, YLi-Urpo A, Vallittu PK. An introduction to silanes and their clinical applications in dentistry. Int J Prosthodont 2004; 17: 155-164.

13) International Standardization Organization(ISO). DentistryPolymer-based crown and bridge materials, Amendment 1996; ISO 10477.

14) Seimenis I, Sarafianou A, Papadopoulou H, Papadopoulos T. Shear bond strength of three veneering resins to a Ni-Cr alloy using two bonding procedure. J Oral Rehabil 2006; 33: 600608.

15) Mukai M, Fukui H, Hasegawa J. Relationship between sandblasting and composite resin-alloy bond strength by a silica coating. J Prosthet Dent 1995; 74: 151-155.

16) Yoshida K, Kamada K, Atsuta M. Adhesive primers for bonding cobalt-chromium alloy to resin. J Oral Rehabil 1999; 26: $475-478$.

17) Ohno H, Araki Y, Sagara M, Yamane Y. The adhesion mechanism of dental adhesive resin to the alloy. Experimental evidence of the deterioration of bonding ability due to adsorbed water on the oxide layer. Dent Mater J 1986; 5: 211-216.

18) Matsumura H, Yanagida H, Tanoue N, Atsuta M, Shimoe S. Shear bond strength of resin composite veneering material to gold alloy with varying metal surface preparations. J Prosthet Dent 2001; 86: 315-319.

19) Jacobson TE, Chang JC, Keri PP, Watanabe LG. Bond strength of 4-META acrylic resin denture base to cobalt chromium alloy. J Prosthet Dent 1988; 60: 570-576.

20) Tanaka T, Nagata K, Takeyama M, Atsuta M, Nakabayashi N, Masuhara E. 4-META opaque resin-a new resin strongly adhesive to nickel-chromium alloy. J Dent Res 1981; 60: 1697-1706.

21) Canay S, Hersek N, Tulunoglu I, Uzun G. Effect of 4-META adhesive on the bond strength of different metal framework designs and acrylic resin. J Oral Rehabil 1997; 24: 913-919.

22) Urapepon S, Kakuta K, Ogura H. Development of metalresin composite restorative material: Part5 Evaluation of the bonding between Ag-Sn particle and 4-META coupling agent of the metal-resin composite. Dent Mater J 2003; 22: 137 145 .

23) Matinlinna JP, Heikkinen T, Özcan M, Lassila LV, Vallittu PK. Evaluation of resin adhesion to zirconia ceramic using some organosilanes. Dent Mater 2006; 22: 824-831.

24) Kurata S, Yamazaki N. Effect of silane coupling agents with a bifunctional hydrolyzable group. Dent Mater J 1993; 12: 127 135 .

25) Matinlinna JP, Özcan M, Lassila LV, Vallittu PK. The effect of a 3-methacryloxypropyl-trimethoxysilane and vinyltriisopropoxysilane blend and tris(3trimethoxysilylpropyl) isocyanurate on the shear bond strength of composite resin to titanium metal. Dent Mater 2004; 20: 804-813.

26) Matsumura H, Kawahara M, Tanaka T, Atsuta M. A new porcelain repair system with a silane coupler, ferric chloride, 
and adhesive opaque resin. J Dent Res 1989; 68: 813-818.

27) Appeldoorn RE, Wilwerding TM, Barkmeier WW. Bond strength of composite to porcelain with newer generation porcelain repair system. J Prosthet Dent 1993; 70: 6-11.

28) Plueddemann EP. Silane and other coupling agents. New York: A Division of Plenum Publishing Corporation; 1991. p. 56-63.

29) Matsumura H, Tanoue N, Atsuta M. Adhesive bonding of stainless steels and their component metals. J Oral Rehabil 2000; 27: 1054-1059.

30) Taira Y, Matsumura H, Yoshida K, Tanaka T, Atsuta M. Adhesive bonding of titanium with a methacrylate-phosphate primer and self-curing adhesive resins. J Oral Rehabil 1995; 22: 409-412.

31) Koizumi H, Furuchi M, Tanoue N, Yanagida H, Yoneyama T, Matsumura $\mathrm{H}$. Bond strength to primed Ti-6Al-7Nb alloy of two acrylic resin adhesives. Dent Mater J 2006; 25: 286-290.

32) Attia A, Lehmann F, Kern M. Influence of surface conditioning and cleaning methods on resin bonding to zirconia ceramic. Dent Mater 2011; 27: 207-213.

33) Barghi N, Berry T, Chung K. Effects of timing and heat treatment of silanated porcelain on the bond strength. J Oral Rehabil 2000; 27: 407-412. 